\title{
Antiphospholipid syndrome (APS) thrombosis sinus sagittalis superior, sinus transversus etsinus sigmoideus, oral contra ception, is there any connection?
}

\begin{abstract}
Success of family planning is based on the usage of contraceptives/a method of conception prevention. Contraceptives should be unharmful, acceptable to everyone, cheap and of course efficient. Hormonal contraception is based on the artificially created state similar of pregnancy suppression of ovulation. Oral contraception can be single phase; two phases or it can be preparation with long term effects implants IUD with hormonal addition. They contain estrogen and progestin. They are recomenmended to the adolescents after $6 / 12$ cycles up to 35 years smokers. The counter effects are vascular ailments, liver ailments. Intra uterus contraception is based on the fact that a foreign body in the uterus makes pregnancy difficult and prevents it. It has dated since 1950. Later copper, silver and progesterone added. Counter effects are bleeding, painful syndrome, spontaneous expulsion. Condoms protect from sexually transmissible diseases.
\end{abstract}

Keywords: antiphospholipid syndrome, thrombosis, oral contraception
Volume I Issue I - 2014

\section{Pekic Ivana}

Primary Health Centre Belgrade, Serbia

Correspondence: Pekic Ivana, Primary Health Centre Grocka, Ljermontova I3, Belgrade, Serbia, Tel 0038I64|431059, Fax 0038 I I 347552 I, Email ivanapekic187@gmail.com

Received: August 21, 2014 | Published: September 12, 2014
Abbreviations: APS, antiphospholipid syndrome; LA, lupus anticoagulant; ACL, anticardiolipin; GP, glycoprotein; RA, rheumatic arthritis

\section{Introduction}

Antiphospholipid Syndrome (APS) is disorder which is characterized by recurrent thrombosis (veins or arterial) or by spontaneous miscarriage accompanied with lab. Abnormalities include (high level of Antiphospholipid antibodies-APL). APL is directed against anionphospholipide membrane (cardiolipin) or with them connected plasma proteins (2 glycoprotein-1) or complex of phospholipide plasma proteins (lupus anticoagulantLA, anticardiolipin at-aCL, anti 2 glycoprotein-lat-a2GP-I). LA are immunoglobulin class IgG or IgM which when joined with their a.b., they prolong the time of coagulation. ${ }^{1}$ It comes to the intercourse of components of homeostatic system, when the process of homeostase becomes disfunctional. The overcoming of the precoagulation systems leads to recurrent thrombosis. With the help of clinical criterions, it is necessary that least one laboratory criterum exists (presence of A or moderate high level of aCL or 2 GP-T (IgG or IgM).

Primary APS is isolated (without clear clinical signs) and secondary is accompanied with series of the other diseases (SLE, rheumatic arthritis, HIV, pernicious anemia) as well as application of certain medicines (Procainamide, propranolol, oral contraceptives, and amoxicillin). Profilactical treatment means prevention of undesirable clinical events. We should eliminate risk factors-smiking, hypertension, hyperglycemic, application of oral contraception. Clinical manifestation of vascular thrombosis demands application of anticoagulants.

\section{Case presentation}

By reviewing this case we won't to point out doctors dilemmas. In the Primary health care patients, themselves, in spite of doctor's engagement make decisions which can have heavy consequences for them. Patient G.M. 1964, 2 birds (pervias naturales), $1 \mathrm{ab}$. Spontaneous (hbd VI), checked and treated in our application of IUD (Biocuprum) was done at the age of 23. Extracted after 2 years, after that the patient had successful second pregnancy (Diabetes gestations), after six months, spontaneous miscarriage (hbd VII) happens (pregnancy desired). In the next four year period she uses Frilavon pills as contraception (with previous lab treatment) between the age 26 and $30 .{ }^{2}$ Third application of IUD (Biocuprum) rescheduled in a peaceful four year period. After extraction of IUD the patient was treated from unilateral adenitis. After being recovered the patient had IUD (Biocuprum) applied which was extracted after a five-year period (January). Then she was 40 next checks-up followed after six months. Unfortunately no which was hard to recognize her. Actually she used, without consultations with her gynecologist, as a 40 year-old, smoker, on self-initiative, for two months longest pills. In May she reported to the Urgent centre, after which fallowed hospitalization at neurological department. Hospitalized because of her headaches, vomiting, faintness and sharp pain at back of her head. After done CT of the brain, subdural collection of blood, cerebellary and intra hemispherical, was detected. On the done panan angiography DSA, seen Thrombosis of sagittal sinus, sinus transverses and Sinus sigmoideus (the evidence about usage of oral contraceptives exists). Concerning additional diagnosis, the consultation with hematologist done which shows decreased PCG that indicate one of thrombophilias, type protein C or protein $\mathrm{S}$ failure, or resistance on the activated $\mathrm{C}$ protein. She was treated with high levels of Heparin. Hospitalization lasted for 29 days. 
The conclusion of the letter of dismissal says 'Diagnosis of sinus sagittalis superior thrombosis, sinus transverses and Sinus sigmoideus of the right side". Excluded and genetic mutations of factors II, V, VII, XII, disorder of the natural coagulations inhibitors-protein C and $\mathrm{S}, \mathrm{APCR}$. The only parameter which deviated from the normal value was LAC. In the etiology of thrombophilias takes part the usage of the oral contraception.

The patient is still being checked up within our department.

\section{Discussion}

Cooperation between patient and physician is the foundation of good health care.

\section{Acknowledgments}

None.

\section{Conflicts of interest}

Author has no any conflict of interest to declare.

\section{References}

1. Galli M, Luciani D, Bertolini G, et al. Lupus anti coagulants are stronger risk factors for thrombosis than anticardiolipin antibodies in the anti phospholipid syndrome: a systematic review of the literature. Blood. 2003;101(5):1827-1832.

2. Asherson RA, Cervera R, Piette JC, et al. Catastrophic antiphospholipid syndrome clues to pathogenesis from a series of 80 patients. Medicine (Baltimore). 2001;80(6):355-377. 